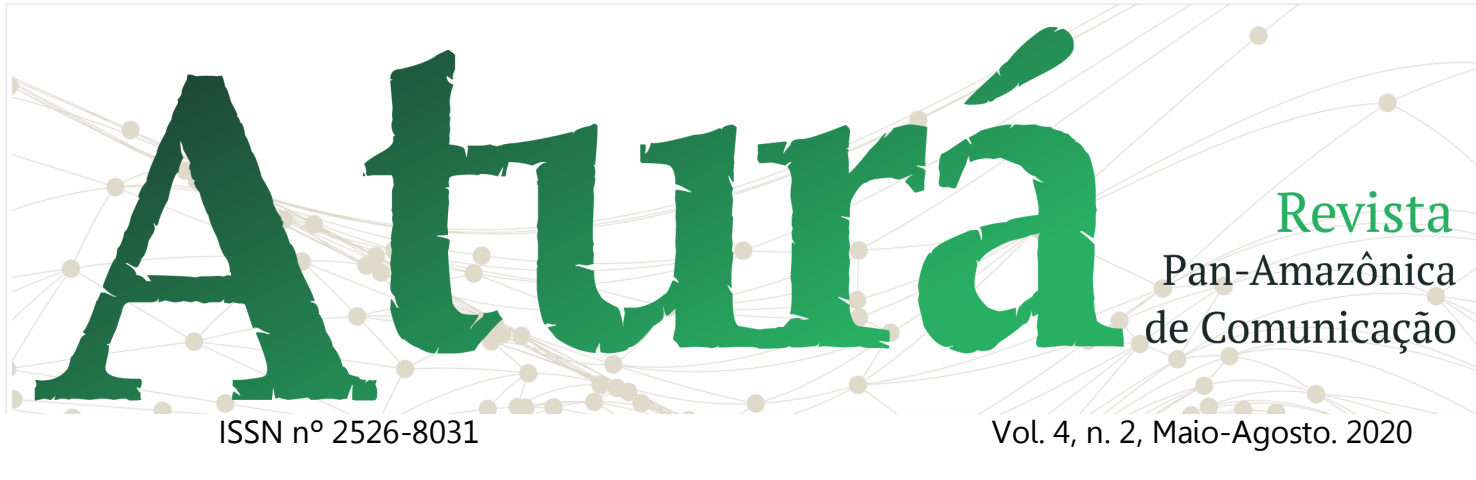

DOI: http://dx.doi.org/10.20873/uft.2526-8031.2020v4n2p38

\title{
COVID-19 E GOVERNO: a cobertura do país vizinho nos sites dos jornais Folha de São Paulo e Clarín durante a pandemia
}

Covid-19 and government: coverage of the neighboring country on the websites of Folha de São Paulo and Clarín during the pandemic

Covid-19 y gobierno: cobertura del país vecino en los sitios web de los periódicos Folha de SãoPaulo y Clarín durante la pandemia

Eduardo Ritter, Universidade Federal de Pelotas ${ }^{1}$

\section{RESUMO}

$\mathrm{Na}$ formação da América Latina, Brasil e Argentina percorreram caminhos semelhantes. Foram formados por uma colonização europeia que dizimou os nativos, tornaram-se fonte de matéria prima para a Europa, participaram de guerras, tiveram governos populistas e ditaduras até chegar ao sistema democrático na última parte do século XX. No entanto, com a pandemia do Covid-19 tomaram caminhos distintos. A diferença nas relações do governo brasileiro e argentino com a pandemia foi abordada pelos maiores jornais de ambos os países: Folha de São Paulo e Clarín. Assim, através da Análise de Conteúdo, este estudo apresenta como cada jornal tratou as ações do governo vizinho durante a maior crise de saúde e econômica no século XXI e uma das maiores da história do mundo contemporâneo. Foram coberturas diferentes para relações distintas.

PALAVRAS-CHAVE: Cobertura jornalística; América Latina; Covid-19; Brasil; Argentina.

\begin{abstract}
During the formation of Latin America, Brazil and Argentina ran throughon similar ways. The two countries were formed by a colonization of Europe that exterminated the natives, have become a source of the raw material for Europe, participated in wars, had populist governments and dictatorships until reaching the democratic system in the last part of the

${ }^{1}$ Doutor em Comunicação Social. Professor de Jornalismo na Universidade Federal de Pelotas (UFPel). E-mail: rittergaucho@hotmail.com.
\end{abstract}




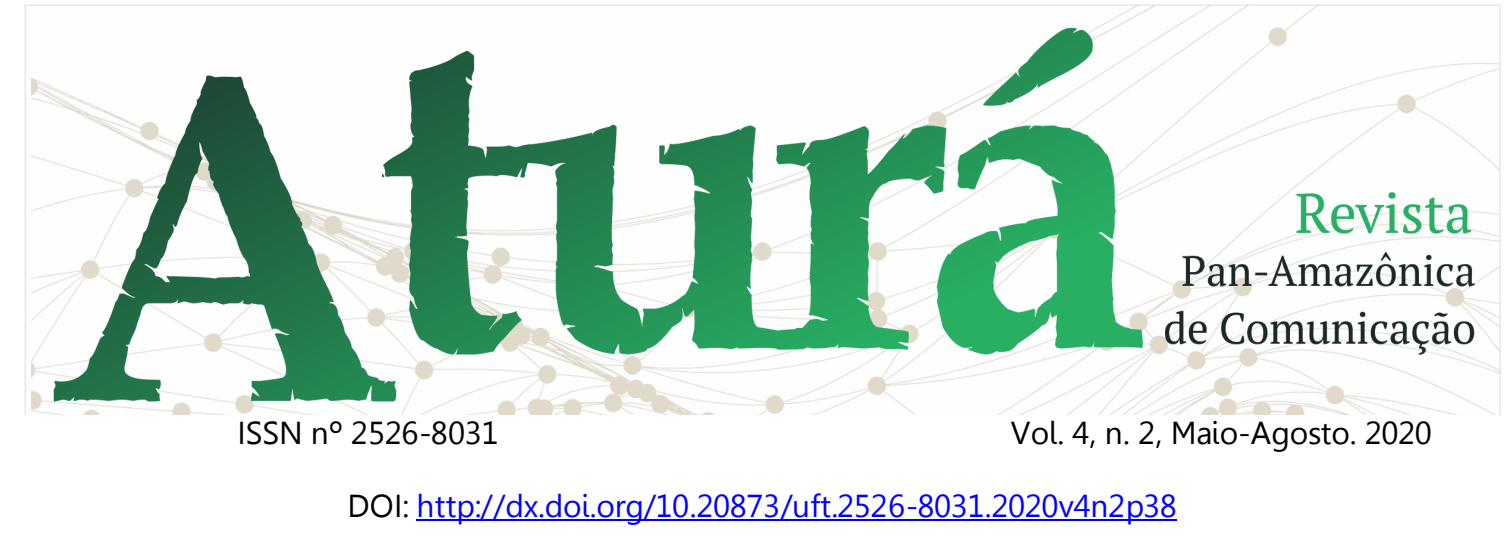

20th century. However, with the Covid-19 pandemic they took different ways. The difference in the Brazilian and Argentine government's relations with the pandemic was addressed by the largest newspapers in both countries: Folha de São Paulo and Clarín. Thus, through Content Analysis, this study presents how each newspaper dealt with the actions of the neighboring government during the worst health and economic crisis in the 21 st century and one of the largest in the history of the contemporary world. There were different coverages for different relationships.

KEYWORDS: Journalistic coverage; Latin America; Covid-19; Brazil; Argentina.

\section{RESUMEN}

En la formación de América Latina, Brasil y Argentina siguieron caminos similares. Fueron formados por una colonización europea que diezmó a los nativos, se convirtió en una fuente de materia prima para Europa, participó en guerras, tuvo gobiernos populistas y dictaduras hasta llegar al sistema democrático en la última parte del siglo XX. Sin embargo, con la pandemia de Covid-19 tomaron diferentes caminos. La diferencia en las relaciones del gobierno brasileño y argentino con la pandemia fue abordada por los periódicos más grandes de ambos países: Folha de São Paulo y Clarín. Así, a través del Análisis de Contenido, este estudio presenta cómo cada periódico lidió con las acciones del gobierno vecino durante la mayor crisis económica y de salud en el siglo XXI y una de las más grandes en la historia del mundo contemporáneo. Hubo diferentes coberturas para diferentes relaciones.

PALABRAS CLAVE: Cobertura jornalística; América Latina; Covid-19; Brasil; Argentina.

Recebido em: 12.02.2020. Aceito em: 14.04.2020. Publicado em: 01.05.2020. 


\section{A \\ ISSN n $2526-8031$ \\ Vol. 4, n. 2, Maio-Agosto. 2020 \\ DOI: http://dx.doi.org/10.20873/uft.2526-8031.2020v4n2p38}

\section{Introdução}

A América Latina é a região das veias abertas, como sintetizou Galeano (1989). É um continente extenso, populoso, com muitas riquezas naturais e multiculturais. Mas também é o continente onde os países dialogam muito pouco e, apesar das proximidades geográficas, as populações pouco sabem sobre seus vizinhos. Era assim nos tempos da colonização e é assim hoje, apesar de toda a tecnologia. De certa forma, a América Latina segue sendo "um arquipélago de países desconectados entre si" (GALEANO, 1989, p.278). Principalmente se for considerado que a América Latina vai muito além dos países sul-americanos, pois conforme aponta Ribeiro (1977) estão inclusos nessa classificação todos os países de colonização latina nas Américas.

Na América do Sul, onde estão os dois países sedes dos veículos selecionados para a análise, pode ser feita uma subdivisão entre a América Platina
(Uruguai e Argentina), a América Andina, que compreende uma área de mais de 3.000 quilômetros de extensão que "vai do Norte do Chile ao Sul da Colômbia, cobrindo os territórios atuais da Bolívia, Peru, Equador e nas encostas que descambam para o Pacífico" (RIBEIRO, 1977, p. 152), além do Brasil, das Guianas e do Suriname, esses três últimos, os únicos que não tem o espanhol como idioma oficial.

Feita essa breve consideração, destaca-se que esse artigo integra uma pesquisa maior sobre o jornalismo e suas (des) conexões na América Latina. Nesse recorte, optou-se por analisar como se da o olhar sobre o vizinho latino-americano a partir dos sites dos dois jornais com maior circulação nos dois maiores países da América do Sul: Argentina e Brasil. Destarte, definiram-se como objeto de estudo as notícias publicadas nos dois sites na última semana de abril de 2020, momento em que o mundo, vive uma pandemia de Covid-19; e Brasil e 


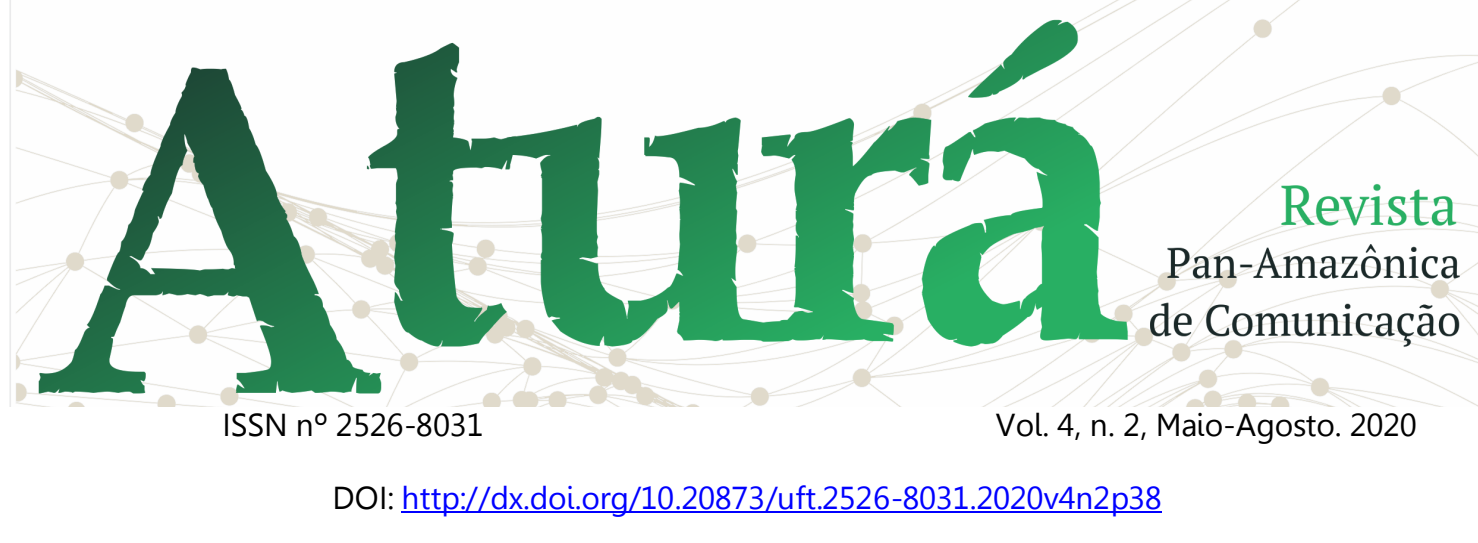

Argentina passam por experiências completamente diferentes de governabilidade: enquanto o Brasil é governado por Jair Bolsonaro, polemista de extrema direita, a Argentina é comandada por Alberto Fernández, ideologicamente autodeclarando como pertencendo à esquerda daquele país.

A partir disso, elencou-se a seguinte questão norteadora de pesquisa: como o jornal Folha de São Paulo cobriu a relação Covid-19 e governo argentino? Em contrapartida, como o jornal Clarín cobriu a relação entre o governo brasileiro e a pandemia? Assim, tem-se como objetivo geral analisar as notícias da última semana de abril publicadas nos sites sobre o tema supracitado. Estruturalmente, o texto começa apresentando os procedimentos metodológicos. Posteriormente é feita uma breve contextualização histórica da América Latina, com ênfase nos dois países mencionados. Em um terceiro momento é apresentado sinteticamente os dois jornais selecionados para, por fim,

ser feita a análise das notícias sobre a temática.

\section{Análise de conteúdo e técnicas metodológicas}

Para fazer a análise proposta, julgou-se apropriada a utilização da Análise de Conteúdo, de Bardin (2011), procedimento metodológico que é "um conjunto de instrumentos cada vez mais sutis em constante aperfeiçoamento, que se aplicam a 'discursos' (conteúdos e continentes) extremamente diversificados" (BARDIN, 2011， p.15). Herscovitz, por sua vez, compara o trabalho do pesquisador ao de detetives que busca pistas "que desvendem os significados aparentes e/ou implícitos dos signos, e das narrativas jornalísticas, expondo tendências, conflitos, interesses, ambiguidades ou ideologias presentes nos materiais examinados" (HERSCOVITZ, 2008, p. 123).

Bardin (2011) apresenta as três etapas da Análise de Conteúdo, utilizadas nessa pesquisa: a primeira fase é a pré- 


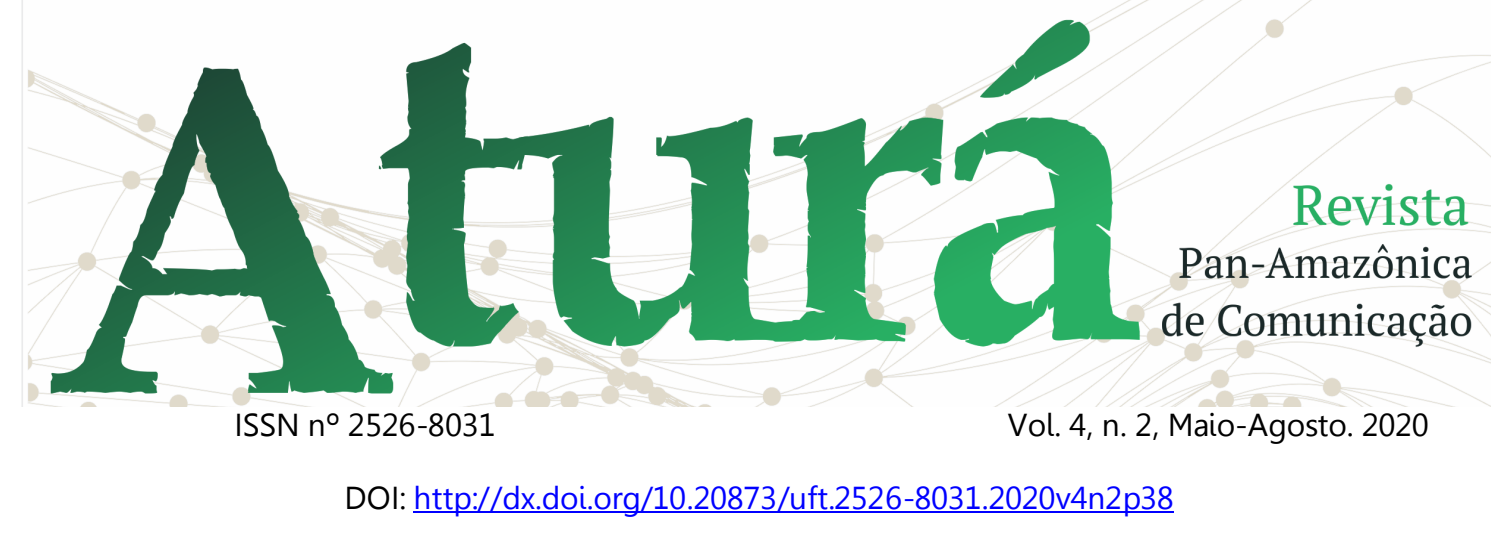

análise, que remete a uma fase de Assim, para a análise das notícias organização. Nessa etapa, o pesquisador escolhe o material a ser submetido à análise, a formulação das hipóteses e dos objetivos, além da elaboração dos indicadores para a interpretação final. A segunda fase é a de exploração do material. "Se as diferentes operações da pré-análise forem convenientemente concluídas, a fase de análise propriamente dita não é mais do que a aplicação sistemática das decisões tomadas" (BARDIN, 2011, p.131). Por fim, a terceira prevê o tratamento dos resultados obtidos e interpretação. Nessa etapa os resultados brutos são tratados para serem significados e validados. Para tanto, outro elemento importante é a inferência. Para a autora, o interesse dos resultados está, sim, "no que estes nos poderão ensinar após serem tratados (por classificação, por exemplo) relativamente à 'outras coisas'" (BARDIN, 2011, p.44). A inferência consiste no processamento de derivação feita a partir dos dados e tidos como verdadeiros. publicadas sobre o país vizinho
publicadas nos sites dos jornais Folha de São Paulo e Clarín, elas foram inicialmente quantificadas e divididas conforme a temática predominante. Posteriormente, foram separadas as que tratam da relação entre governo e Covid19 para serem reclassificadas conforme o seu conteúdo, sendo descritas e analisadas, com a observância do texto suas características jornalísticas. 0 período selecionado é a semana entre os dias 24 e 30 de abril de 2020, fazendo um recorte ilustrativo sobre como foi a cobertura da relação entre Covid-19 e governos brasileiros e argentinos pelos dois supracitados jornais.

Isso posto, vale salientar que há ocasiões em que se emprega a pesquisa quantitativa, que são pesquisas que "têm como objetivo medir ou calcular, isto é, quantificar algum aspecto do comportamento humano" (MARTINO, 2018, p.101), bem como há conjunções para a pesquisa qualitativa, pois ela é 


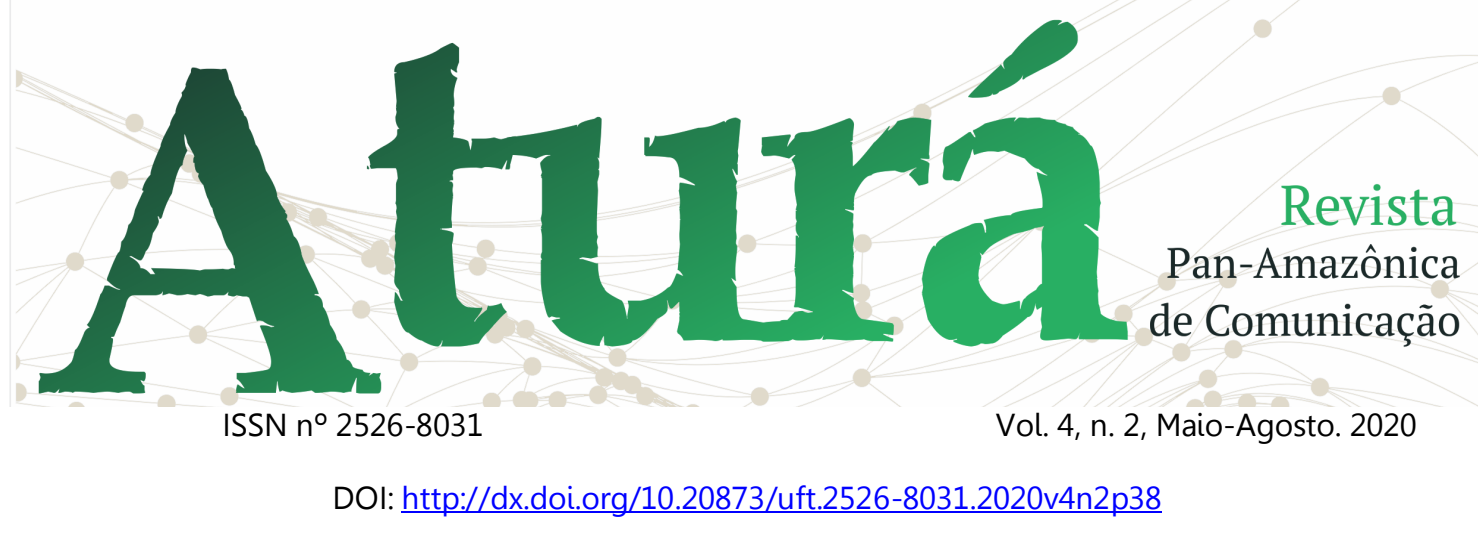

fundamental para que se interprete os dados levantados.

América Latina: história, formação e distanciamentos

Brasil e Argentina, assim como outros países latinos da América do Sul, tiveram trajetórias de formação social, política e econômica semelhantes. Ainda no período colonial, eles foram palco de disputas entre os povos europeus, especialmente espanhóis e portugueses, para a definição da nova divisão espaçogeográfica imposta pelos que chegaram. Para isso, não houve na América Latina uma região onde os povos indígenas não fossem massacrados pelos colonizadores europeus.

As matanças dos indígenas começaram com Colombo e nunca cessaram. No Uruguai e na Patagônia argentina, os índios foram exterminados, no século passado $[X I X]$, por tropas que os buscaram e os encurralaram nos bosques ou no deserto, com o objetivo de que não atrapalhassem o avanço organizado dos latifúndios do gado (GALEANO, 1989, p.59).

A logística econômica, e que resultou na formação de abismos sociais em cada país latino-americano, também foi semelhante no Brasil e na Argentina, apesar dos colonizadores serem oriundos de países europeus diferentes. De maneira geral, como aponta Galeano (1989), a riqueza encontrada era rapidamente trocada por mercadorias utilitaristas da Europa, produzidas principalmente pela Inglaterra, que também mantinha Portugal e Espanha sempre endividados, tornando-se apenas países de passagem da riqueza que chegava do então chamado Novo Mundo. Em síntese, a colônia exportava matéria prima barata e comprava os produtos a preços altos. $E$, para vender a matéria prima a valores insignificantes era preciso manter a mão de obra escrava. "Ouro, prata, açúcar: a economia colonial, mais abastecedora do que consumidora, estruturou-se em função das necessidades de mercado europeu e a seu serviço" (GALEANO, 1989, p.40).

A proximidade geográfica também foi fundamental para que fossem criadas relações e distanciamentos entre alguns 


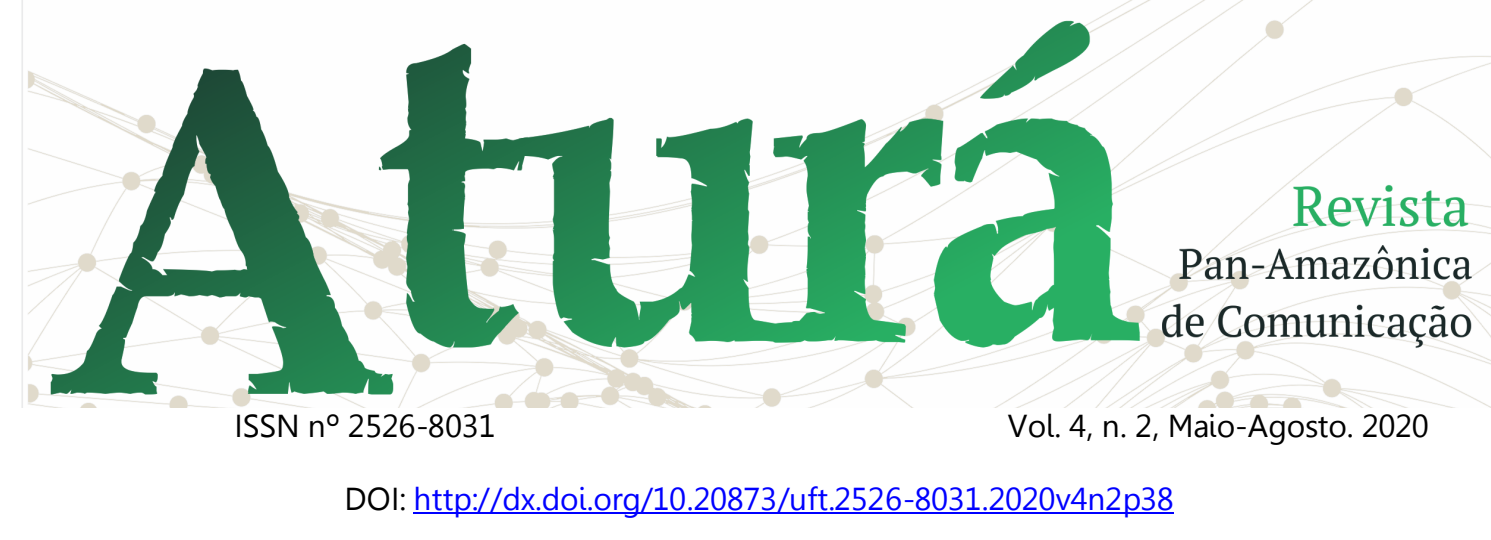

países latinos. Na América do Sul, a tecnologias de comunicação foi Guerra do Paraguai (1864-1870), por exemplo, uniu Uruguai, Brasil e Argentina para derrubar 0 ditador paraguaio Francisco Solano López. O maior conflito armado do continente na era póscolonização resultou na derrota econômica e social de todos os envolvidos. Se do lado paraguaio praticamente toda a população masculina foi executada (preço social e econômico que o Paraguai paga até hoje), os vencedores também pagaram caro: "A invasão foi financiada, do começo ao fim, pelo Banco de Londres, a Casa Baring Brothers e banco Rothschild, em empréstimos com juros leoninos que hipotecaram 0 destino dos países vencedores" (GALEANO, 1989, p.205).

No século XX, Brasil e Argentina seguiram tendo histórias semelhantes. Enquanto Getúlio Vargas (1882-1954) foi o maior populista brasileiro, na Argentina Juan Perón (1895-1972) conseguiu a mesma representatividade política e histórica. Para tanto, a utilização das fundamental. Afinal, como mostra Barbero (2013) inicialmente a literatura, posteriormente o jornalismo impresso e o rádio e, mais adiante, a televisão, foram fundamentais para que cada país latinoamericano constituísse uma ideia de nação. Getúlio e Perón, cada um em seu país, tiveram notável consciência disso e usaram essas ferramentas a seu favor.

Aliás, a cultura dos países latinos também segue a lógica global e sempre foi um campo de disputa pelo poder, afinal, na transição de um capitalismo agrário para um capitalismo industrial "houve uma luta mais ou menos contínua em torno da cultura dos trabalhadores, das classes trabalhadoras e dos pobres" (HALL, 2009, p.231). Já Canclini (2013), pesquisando sobre a cultura latinoamericana, destaca a fundição entre estruturas e práticas sociais para gerar novas estruturas e normas. Isso não é planejado e tão pouco previsto, mas sim, "é resultado imprevisto de processos migratórios, turísticos e de intercâmbio 


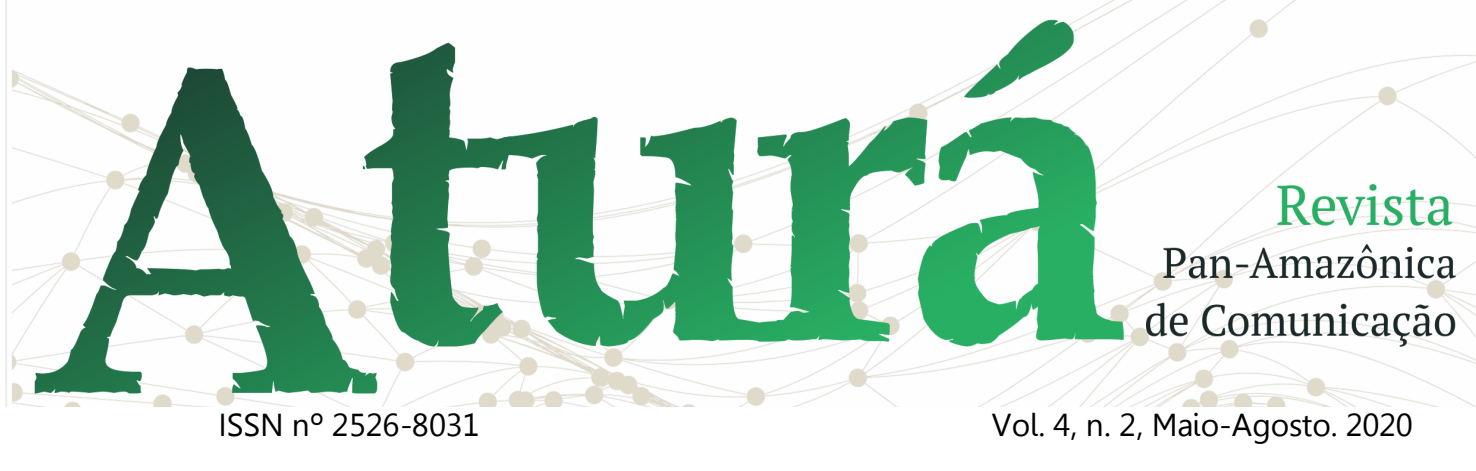

DOI: http://dx.doi.org/10.20873/uft.2526-8031.2020v4n2p38

econômico ou comunicacional" (CANCLINI, 2013, p. XXII).

Politicamente, Brasil e Argentina, juntamente com Chile, Bolívia, Paraguai e Uruguai, atuaram em parceria durante a Guerra Fria no que ficou conhecido como Operação Condor: a ação coordenada das ditaduras militares dos países latino-sulamericanos com os Estados Unidos para perseguir e acabar com qualquer movimento de esquerda. Em um episódio específico, Brasil, Argentina e Uruguai atuaram no sequestro de um casal de uruguaios e duas crianças em Porto Alegre, no final de 1978. O episódio é narrado pelo jornalista Luiz Cláudio Cunha, que testemunhou o crime cometido pelo estado brasileiro em parceria com as ditaduras dos países vizinhos.

No balneário, dominado por argentinos que desprezavam a agitação de Mar del Plata, estavam reunidos por três dias os chanceleres dos cinco países da Bacia do Rio da Prata. Cinco tributários da corrente anticomunista. Cinco regimes de quartelada. Cinco ditaduras (CUNHA, 2008, p.117).
Unidos na dizimação da população indígena, na importação de escravos, na ascensão e queda de governos populistas, na ditadura anticomunista, na manutenção de um sistema que privilegia poucos e condena a população ao subdesenvolvimento. Separados quase que exclusivamente por uma rivalidade cultural representada pelo futebol. Rivalidade ampliada por disputas ao posto de melhor seleção, maior economia e maior desenvolvimento social da América do Sul. Países fronteiriços com lindas paisagens naturais. Uma das hipóteses do distanciamento entre países historicamente semelhantes, fronteiriços, mas popularmente tão distanciados, é o idioma.

Na Região Platina, quando a fronteira é tida como lugar de fim, de limite entre Estados, as línguas espanhola, portuguesa e guarani, por serem línguas dos Estados nacionais que a integram, também significam a divisão, a diferenciação entre povos e territórios; já quando a fronteira é vivida como lugar de continuidade, de vizinhança entre Estados, essas línguas, por serem línguas do Mercosul e também locais-fronteiriças, significam o encontro entre as comunidades dos países limítrofes, as suas semelhanças culturais, 


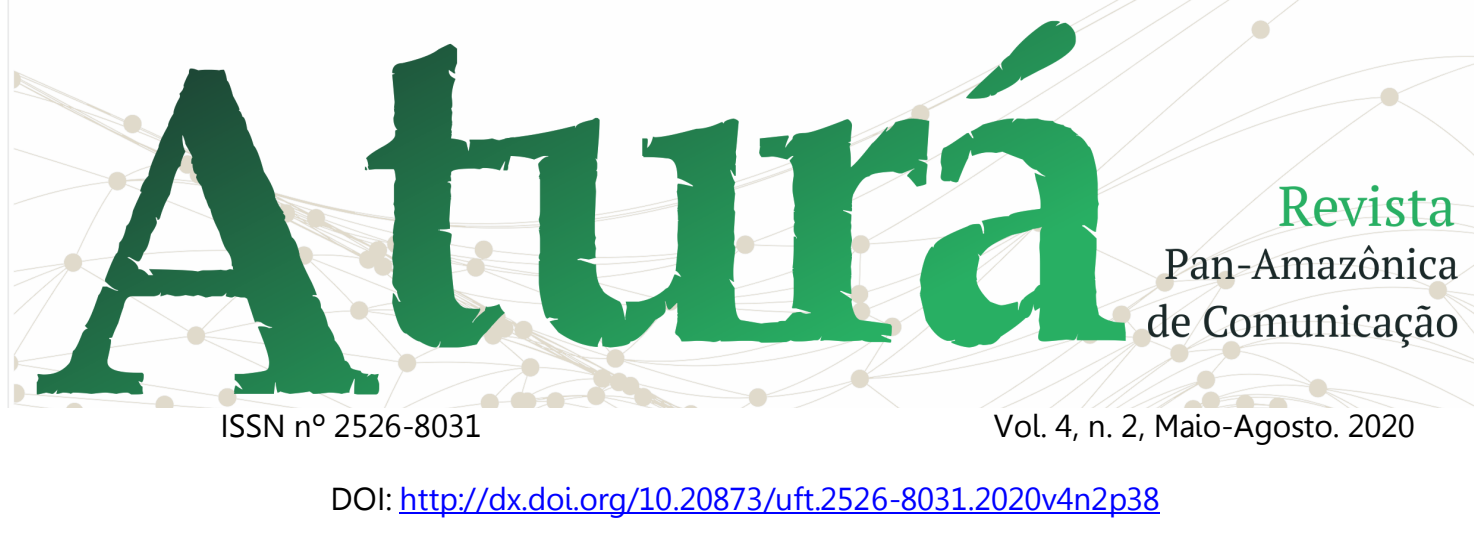

sua proximidade social (WEBER; STURZA, 2015, p.39)

Apesar de alguns antagonismos, a unidade em maior ou menor grau se destaca ao se diferenciar, por exemplo, os países da América do Sul das nações economicamente avançados da América do Norte, como Canadá e Estados Unidos. "Aqui, os componentes se alternam, como a América pobre e a América rica, com posições e relações assimétricas de poder em um polo e dependência do outro" (RIBEIRO, 2012, p.13). Por isso se torna fundamental os estudos sobre como está essa tentativa de ligação entre os arquipélagos desconectados apontados por Galeano (1989) através da internet, e que tem no jornalismo um de seus principais viabilizadores. Conhecendo a realidade dos países vizinhos, principalmente pelas semelhanças históricas, sociais e econômicas, é que é possível romper com os distanciamentos mais agudos e almejar um avanço que, a olho nu, é praticamente impossível de se enxergar. Afinal, "não há razões científicas, nem

outras, que autorizem o sociólogo a declarar que um povo, qualquer que ele seja, incapaz de progredir" (BOMFIM, 1993, p.307).

\section{Folha de São Paulo e Clarín: um breve histórico}

O jornal Folha de São Paulo foi fundado em 1921 por Olavo Olívio Olival Costa, no entanto, uma década depois, foi adquirido por um grupo liderado pelo conde Francisco Matarazzo e por Octaviano Alves de Lima. O jornal mudou de direção novamente em 1945, quando foi comandado por José Nabantino Ramos. Por fim, em 1962, Octavio Frias de Oliveira, juntamente com Carlos Cadeira Filho, compraram o periódico. Frias foi definido como "um exemplo de empresário schumpeteriano que descobriu a sua verdadeira vocação com mais de cinquenta anos" (CONTI, 1999, p.186). Foi assim que Octavio Frias criou o Grupo Folha, que passou a ser administrado pelo filho Luiz Frias a partir de 1992, seguindo com o mesmo comando até hoje.

No meio impresso, a Folha de São Paulo é o jornal de maior circulação no Brasil. Conforme dados do Instituto Verificador de Comunicação referente ao ano de 2019 e publicados em janeiro de 2020, o diário registrou uma tiragem Aıura Kevısıa ranı-Aırıa<ùnica de Comunicação, Palmas, v. 4, n. 2, p. 38-58, mai.-ago. 2020 


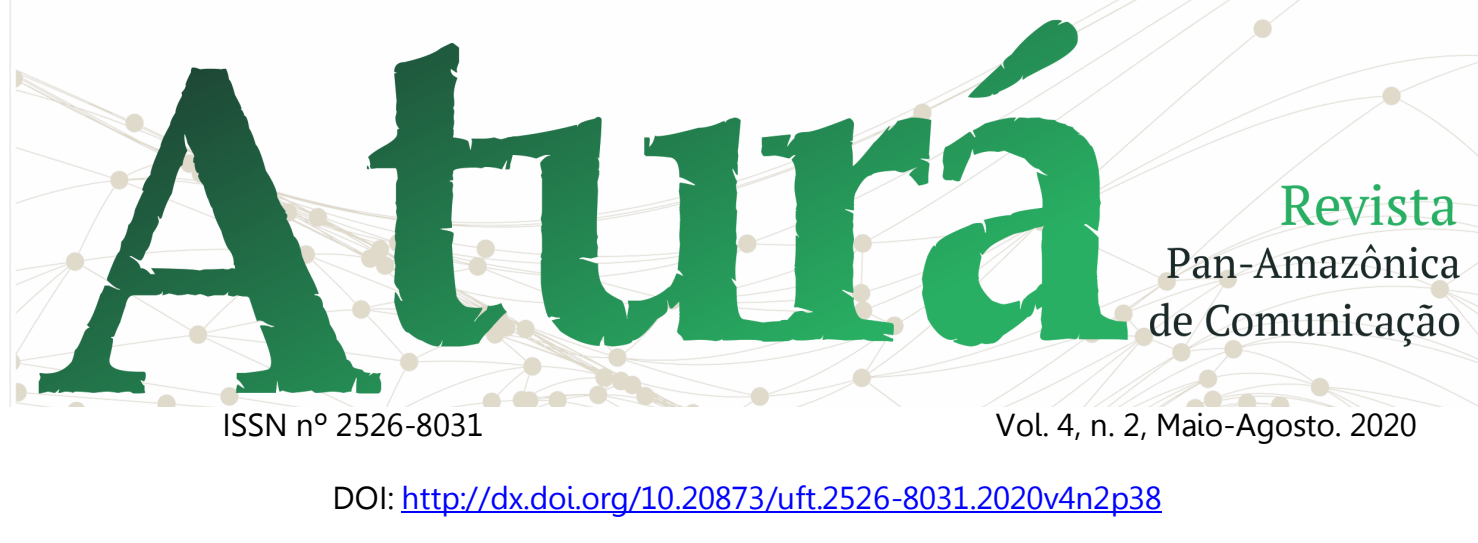

paga diária de 328.438 exemplares. Já no meio digital, conforme o mesmo instituto, a Folha também lidera a média da circulação digital, com 236.059 assinantes. $O$ site do jornal informa ainda que:

No Brasil, a Folha foi pioneira na adoção do sistema chamado de paywall poroso (limite de artigos disponíveis para quem não é assinante ler de graça), estratégia usada também pelos maiores jornais do mundo, como New York Times e Washington Post, por exemplo. Desde então, é líder em assinaturas digitais. ${ }^{2}$

Além disso, a Folha de São Paulo é o jornal com o maior número de seguidores na América Latina se for considerada a soma das três redes sociais de maior número de usuários no mundo online: Facebook, Instagram e Twitter Os dados são de levantamento do Centro Knight, da Universidade do Texas ${ }^{3}$. A mesma pesquisa, feita pelo instituto em 2019, aponta que o jornal argentino

\footnotetext{
2 Disponível em:

https://www1.folha.uol.com.br/poder/2020/01/fol ha-cresce-e-lidera-circulacao-entre-jornais-dopais-em-2019.shtml. Acesso em: 30/04/2019.

Disponível em:

https://knightcenter.utexas.edu/pt-br/. Acesso em: 30/04/2020.

${ }^{3}$ Disponível em:

https://knightcenter.utexas.edu/pt-br/. Acesso em: 30/04/2020.
}

Clarín está em primeiro lugar na América Latina quando o assunto é Facebook. Segundo a investigação, são mais de 6,4 milhões de seguidores na referida rede social.

O jornal Clarín, oficialmente denominado Diario Clarín, é o jornal de maior circulação da Argentina. O diário foi criado em 1945 por Roberto Noble, com orientação ideológica de extremadireita, sendo financiado inicialmente por apoiadores do nazismo alemão que viviam na Argentina. Em 1955 também apoiou o golpe contra o então presidente Juan Domingo Perón. Noble seguiu no comando da empresa até 1969, ano em que faleceu e a administração passou para a viúva Ernestina Herrera de Noble. Ao longo dos anos, adquiriu outros veículos de outras plataformas, como o jornal Olé, que aborda futebol, e a rádio Mitre, agregada em 1990. Em 1995, quando completou meio século, foi lançado oficialmente o Grupo Clarín (BARRETO, 1999). Sob o ponto de vista político, recentemente o Clarín se 


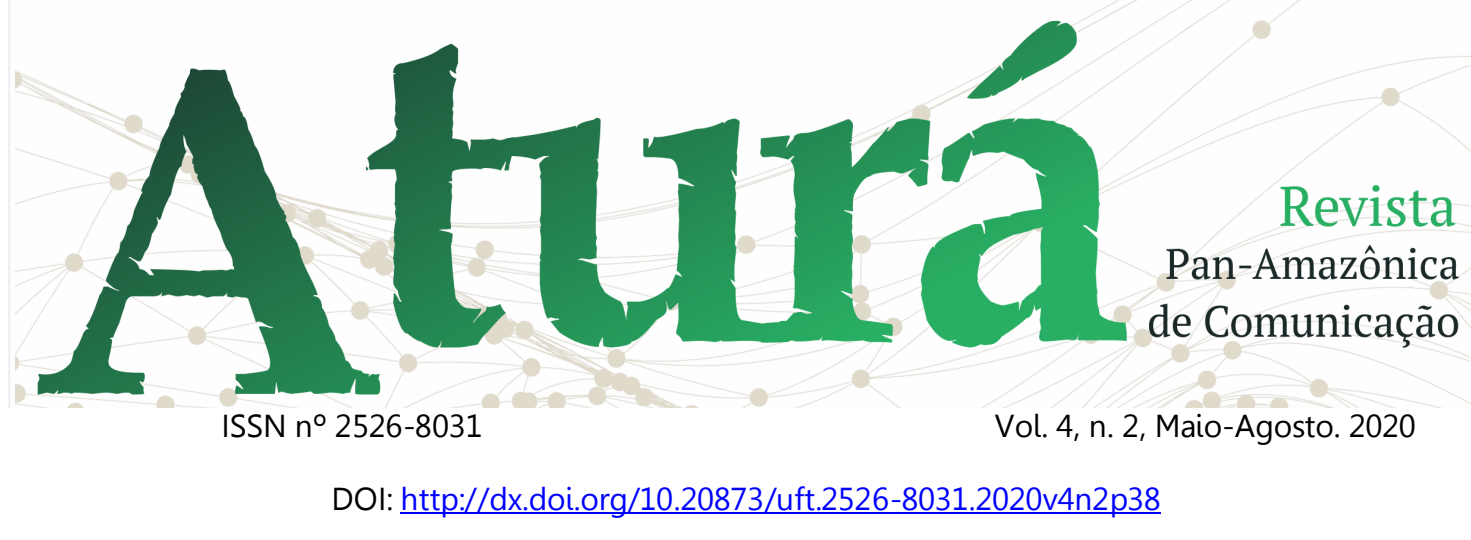

caracterizou por fazer ferrenha oposição Em um primeiro momento, foram ao governo da ex-presidente Cristina Kirchner ${ }^{4}$.

Covid-19 e governo: da discrição argentina nas páginas da Folha ao destaque à crise brasileira no Clarín

Conforme abordado, Brasil e Argentina, além de serem as duas maiores nações da América do Sul e de possuírem históricos sociais, políticos e econômicos semelhantes, também são vizinhos fronteiriços. Nesse cenário, o jornalismo se torna ferramenta fundamental para haver a troca de informações entre argentinos e brasileiros. Destarte, o que é abordado sobre cada um dos países vizinhos nos jornais locais se converte na principal fonte de informação para as populações. Para analisar o enfoque dado ao país vizinho pelos jornais Folha de São Paulo e Clarín foram feitas duas divisões.

${ }^{4}$ Cristina Kirchner foi presidente da Argentina entre 2007 e 2015. Atualmente é vice-presidente do governo Alberto Fernández. analisadas todas as notícias publicadas na seção Brasil do jornal Clarín na semana entre 24 e 30 de abril de 2020. Essas notícias foram divididas em quatro temáticas. A primeira é a crise política, ou seja, notícias que abordam exclusivamente a crise política que envolve o presidente Bolsonaro com as saídas dos ministros da saúde, Luiz Henrique Mandetta, e da Justiça, Sérgio Moro. Na segunda categoria aparecem notícias que tratam do tema Covid-19 de maneira geral, sem o relacionar com questões políticas ou de governo. $\mathrm{Na}$ terceira temática aparecem as que interessam mais para esta pesquisa, que são matérias que abordam as relações entre Covid-19 e o governo brasileiro. Por fim, foi encontrada apenas uma notícia sobre outra temática, classificada como "outros".

\begin{tabular}{|l|l|}
\hline Tema: & $\begin{array}{l}\text { Números de } \\
\text { notícias: }\end{array}$ \\
\hline Crise política & 16 \\
\hline Covid-19 no Brasil & 15 \\
\hline Relação Covid-19 e & 8 \\
\hline
\end{tabular}

Aturá Revista Pan-Amazônica de Comunicação, Palmas, v. 4, n. 2, p. 38-58, mai.-ago. 2020 


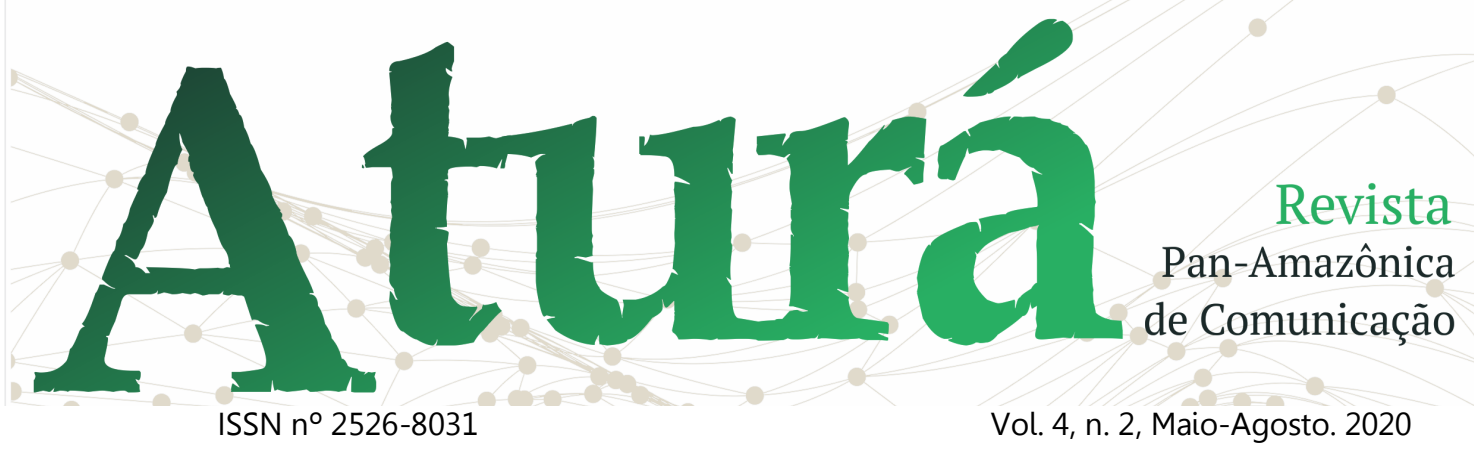

DOI: http://dx.doi.org/10.20873/uft.2526-8031.2020v4n2p38

\begin{tabular}{|l|l|}
\hline governo & \\
\hline Outros (literatura) & 1 \\
\hline Total & 38 \\
\hline
\end{tabular}

Dados levantados entre 24 e 30 de abril de $2020^{5}$

O mesmo foi feito em relação à

seção Argentina no site do jornal Folha de São Paulo, conforme é possível observar na tabela a seguir:

\begin{tabular}{|l|l|}
\hline Tema: & $\begin{array}{l}\text { Números de } \\
\text { notícias: }\end{array}$ \\
\hline Crise política & 0 \\
\hline Covid-19 na Argentina & 4 \\
\hline $\begin{array}{l}\text { Relação Covid-19 e } \\
\text { governo }\end{array}$ & 2 \\
\hline Outros (futebol) & 1 \\
\hline Total & 7 \\
\hline \multicolumn{2}{|l|}{ Dados levantados entre 24 e 30 de abril de $2020^{6}$}
\end{tabular}

Pode-se observar que os números são completamente diferentes. Enquanto em uma semana o Clarín publicou 38 notícias sobre o Brasil, numa média de 5,4 por dia, a Folha de São Paulo publicou apenas sete, média de apenas uma por dia. A temática "crise política" justifica essa diferença, pois é o principal tema

\footnotetext{
${ }^{5}$ Disponível em:

https://www.clarin.com/tema/brasil.html. Acesso em: $01 / 05 / 2020$

${ }^{6}$ Disponível em: https://m.folha.uol.com.br/folhatopicos/argentina/. Acesso em: 01/05/2020
}

abordado pelo Clarín sobre o Brasil, enquanto que esse assunto não aparece relacionado à Argentina na Folha de São Paulo. A maioria das notícias se refere especificamente aos números do Covid19 na Argentina, enquanto apenas duas vezes a Folha de São Paulo apresentou a relação entre o governo argentino e a pandemia.

Posteriormente foram analisadas as notícias sobre a temática Covid-19 relacionadas com o governo de cada país. Algumas não explicitam esse tópico em seus títulos, mas eles aparecem como elemento central no corpo da matéria. $\mathrm{Na}$ tabela a seguir são apresentadas todas as manchetes das notícias relacionadas ao Brasil sobre o assunto no site do Clarín.

\begin{tabular}{|c|c|}
\hline Manchetes do site do jornal Clarín & Data \\
\hline 1. Coronvirus en Brasil: & 25/04 \\
$\begin{array}{l}\text { Golpeado tras las acusaciones } \\
\text { de Sergio Moro, Jair }\end{array}$ & \\
Bolsonaro busca contener la \\
crisis $^{7}$
\end{tabular}

\footnotetext{
7 Disponível em:

https://www.clarin.com/mundo/golpeadoacusaciones-sergio-moro-jair-bolsonaro-buscacontener-crisis_0_o56pEdztc.html. Acesso em: 25/04/2020
} 


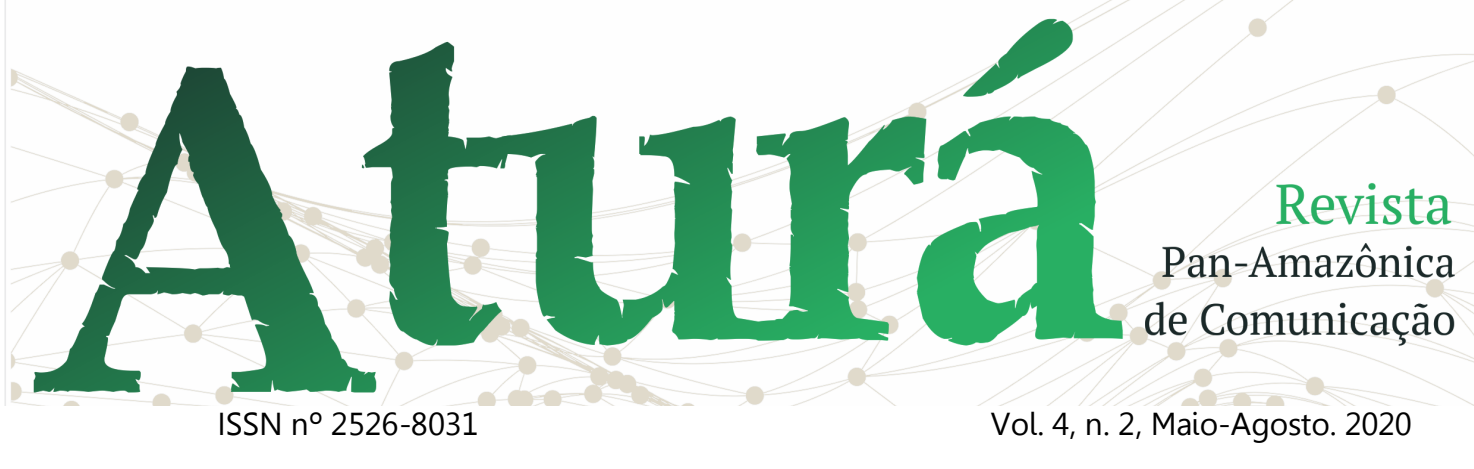

DOI: http://dx.doi.org/10.20873/uft.2526-8031.2020v4n2p38

\begin{tabular}{|l|l|l|}
\hline 2. En medio de una crisis & 26/04 \\
política: Coronavirus en Brasil: & \\
llega a 4.205 muertes, con & \\
más de 61.888 casos de & \\
Covid-198 & \\
\hline 3. Coronavirus en Brasil: "No & $27 / 04$ \\
queremos convertirnos en una & \\
Argentina", dijo el ministro de & \\
Economía de Bolsonaro & \\
\hline 4. Jair Bolsonaro, luego de que & $28 / 04$ \\
Brasil superó a China en & \\
cantidad de muertos por el & \\
coronavirus: "Lo lamento, & \\
iqué quiere que haga?'10 & \\
\hline Coronavirus en Brasil: Jair & $29 / 04$ \\
Bolsonaro se niega a mostrar & \\
los tests de Covid-1911 & \\
\hline 6a hay 5017 fallecidos Jair & $29 / 04$ \\
Bolsonaro, luego de que Brasil & \\
superó a China en cantidad de & \\
muertos por el coronavirus: & \\
"Lo lamento, iqué quiere que & \\
haga?"12 & \\
\hline
\end{tabular}

${ }^{8}$ Disponível em:

https://www.clarin.com/mundo/coronavirusbrasil-llega-4-205-muertes-61-888-casos-covid190 OFaNUX6dz.html. Acesso em: 26/04/2020.

${ }^{9}$ Disponível em:

https://www.clarin.com/mundo/coronavirusbrasil-queremos-convertirnos-argentina-dijoministro-economia-

bolsonaro 0 dMrpYKWpx.html. Acesso em: 27/04/2020.

${ }^{10}$ Disponível em: https://www.clarin.com/mundo/jairbolsonaro-luego-brasil-supero-china-cantidad-muertoscoronavirus-lamento-quiere-haga- $0 \mathrm{~d} \mathrm{HTu}$-d7s.html. Acesso em: 28/04/2020.

${ }^{11}$ Disponível em:

https://www.clarin.com/mundo/coronavirus-brasil-jairbolsonaro-niega-mostrar-tests-covid-19 0 9V098P58.html. Acesso em: 29/04/2010.

${ }_{12}$ Disponível em:

https://www.clarin.com/mundo/coronavirus-brasillamento-quieren-haga-mesias-hago-milagros-defiende-

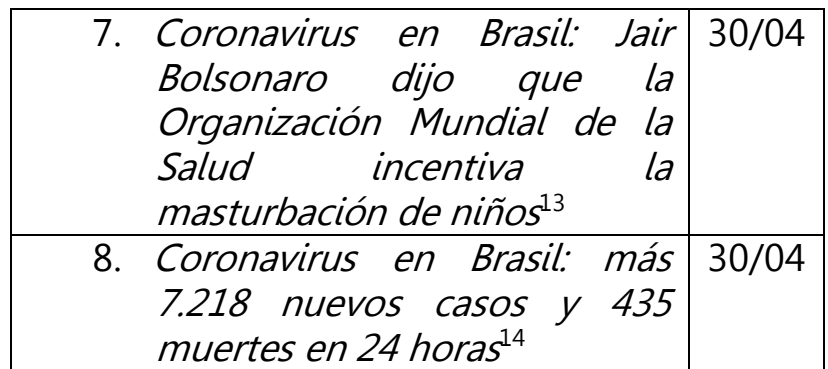

Dados levantados enter 24 e 30 de abril de $2020^{15}$

Conforme aponta Traquina (2005), dois dos principais critérios de noticiabilidade para os jornalistas selecionarem o que vai ser publicado são: espanto e importância do ator principal dos acontecimentos. Além disso, recuperando outras pesquisas, ele apresenta a seguinte classificação para notícias relacionadas às atividades de governo: “a) conflitos e desacordos dentro do governo; b) decisões e

jair-bolsonaro 0 0OfqkG87m.html. Acesso em: 29/04/2020.

${ }^{13}$ Disponível em:

https://www.clarin.com/mundo/coronavirus-brasil-jairbolsonaro-dijo-organizacion-mundial-salud-incentivamasturbacion-ninos 0 S7kG9U6XD.html

${ }^{14}$ Disponível em:

https://www.clarin.com/mundo/coronavirus-brasil-7218-nuevos-casos-435-muertes-24-

horas 0 dq3VHGroa.html. Acesso em: 30 de abril de 2020.

${ }^{15}$ Disponível em:

https://www.clarin.com/tema/brasil.html. Acesso em: $01 / 05 / 2020$ 


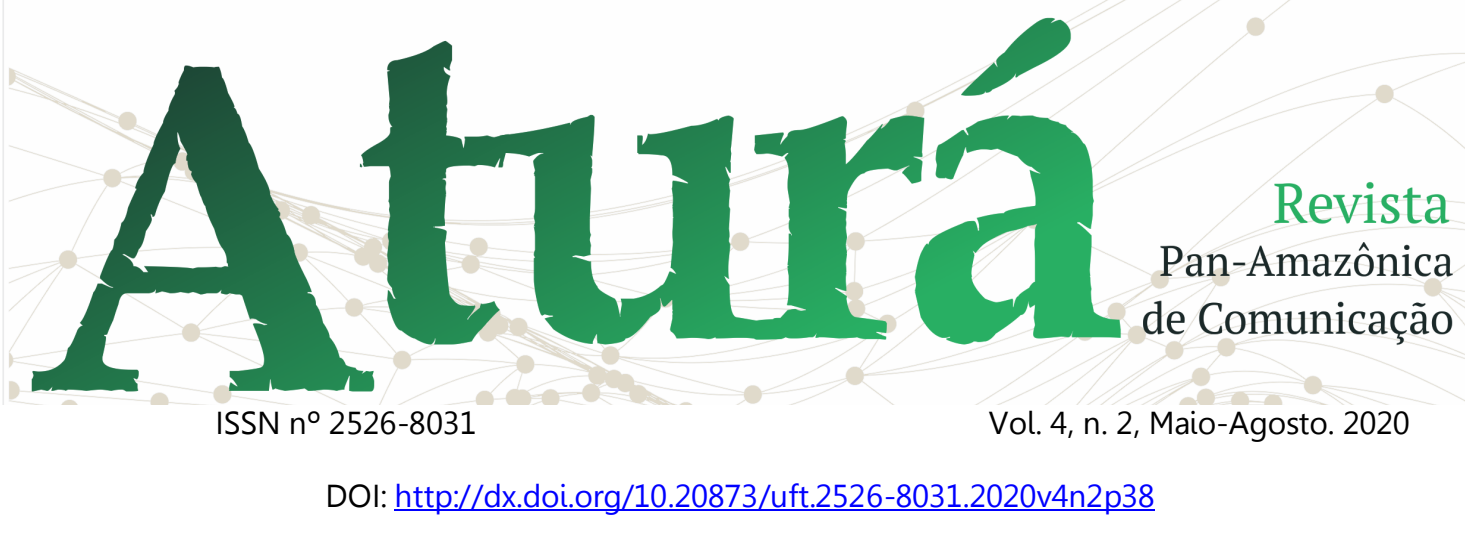

propostas governamentais e cerimônias/ e c) mudanças de pessoas exercendo funções governamentais" (TRAQUINA, 2005, P.68).

Ora, nas manchetes e nos textos publicados pelo Clarín se percebe todos esses elementos. Há a figura do presidente brasileiro envolvido em polêmicas e dando declarações que causam espanto no leitor, além das trocas de pessoas que integram o governo e de ações polêmicas para o combate à pandemia (ou a falta delas). Em uma das matérias que tratam das polêmicas envolvendo o presidente, é destacada uma postagem feita por Jair Bolsonaro no Twitter acusando a Organização Mundial da Saúde (OMS) de incentivar a masturbação e a homossexualidade para crianças. Para auxiliar na interpretação do leitor, o jornalista cita informações verificadas na imprensa brasileira. "Bolsonaro no publicó la fuente de las supuestas directrices. Medios brasileños dijeron que se trataba de una publicación del 2010 dirigida a padres y elaborada

por una entidad médica de Alemania y la oficina europea de la OMS".

Além disso, para demonstrar a veracidade das declarações de Bolsonaro e seus ministros, em duas notícias são utilizados vídeos. Na notícia número 3 da tabela é colocado o vídeo do ministro da economia, Paulo Guedes, falando que não quer que o Brasil se transforme em uma Argentina. "Respaldado por el presidente Bolsonaro, el ministro de Economía Paulo Guedes dijo el lunes que Brasil no quiere convertirse en una Argentina ni en una Venezuela y por eso seguirá por el camino de la prosperidad, abriendo su economía en un marco de estabilidad fiscal", informa o texto abaixo do vídeo. Enquanto que no vídeo número 4 é apresentada uma síntese com as declarações mais polêmicas do presidente brasileiro sobre o Covid-19.

A notícia número 1 da tabela, por sua vez, apresenta no título o desentendimento entre o presidente e o ex-ministro da Justiça, Sérgio Moro. No entanto, é destacado no texto que a crise 


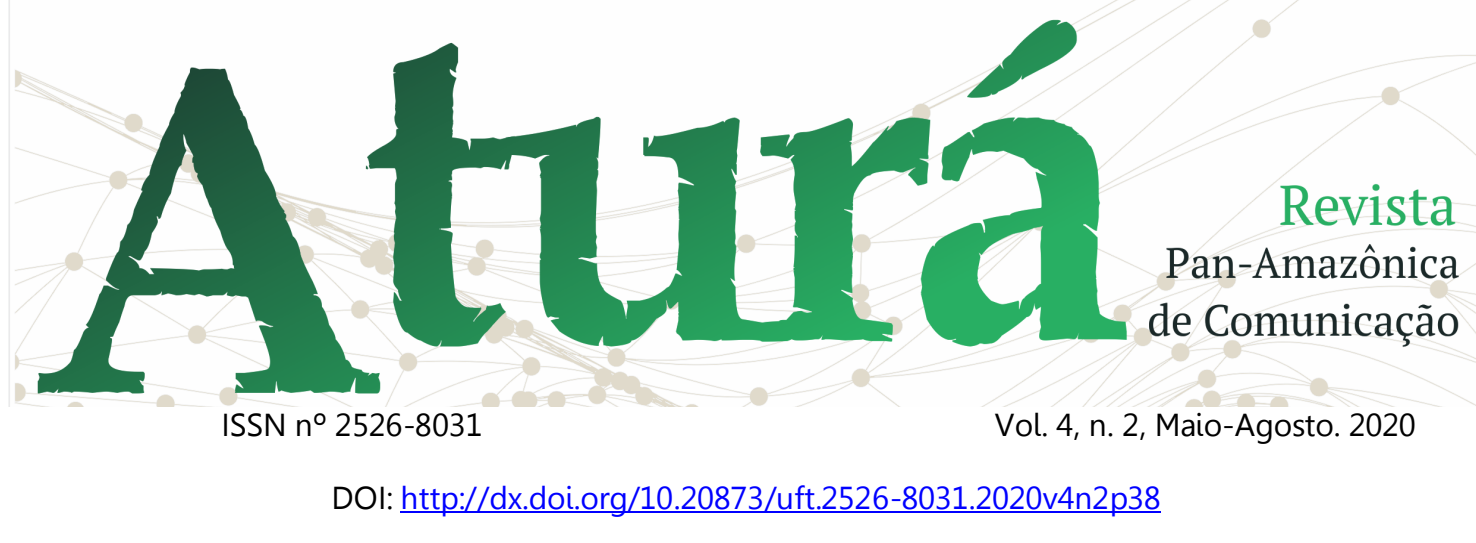

ocorre em meio a uma pandemia. Após apresentar os números do Covid-19 no Brasil, o correspondente do Clarín no país, Guido Nejamkis, apresenta o conflito político: "Pese a ese cuadro, la principal preocupación del gobierno era contener la monumental crisis política que acorrala al presidente Jair Bolsonaro, cuyo primer capítulo fue disparado por un conflicto con el ministro de Salud [...]" (NEJAMKIS, 2020). Já a notícia número 8 da tabela traz o inverso: apresenta no título números da doença, mas comenta ao longo do texto a crise política, que naquele momento era representada pela troca do ministro da Saúde em meio à pandemia.

Analisando as oito notícias do Clarín, percebe-se que elas estão enquadradas no gênero jornalístico interpretativo, proposto por Melo (2012), pois 0 correspondente argentino interpreta os dados e as declarações apresentadas no texto. "Emerge com vigor, embora denotando intensidade sazonal, uma variante de jornalismo analítico-educativo, matriz do gênero interpretativo" (MELO, 2012, p.22). Isso é feito pelo jornalista apresentando dados, declarações das fontes e interpretações, como a verificada em trecho da notícia número 6 da tabela: "Frases chocantes se volvieron habituales en las declaraciones improvisadas y en los discursos de Bolsonaro. En marzo, por ejemplo, dijo que los efectos del coronavirus estaban sobredimensionados y luego aseguró que otras gripes mataron más" (NEJAMKIS, 2020). Utilizar a citação das fontes e dados oficiais também garantem a credibilidade do jornalista, especialmente no meio político. "Hoje em dia, ao contrário, a grande imprensa, de modo geral, tem a preocupação de separar nitidamente a informação da opinião na cobertura política" (MARTINS, 2011, p.17).

Já no jornal Folha de São Paulo foram encontradas apenas duas notícias que fazem, mesmo que discretamente, a relação entre o governo argentino e a situação vivida pelo país em meio à 


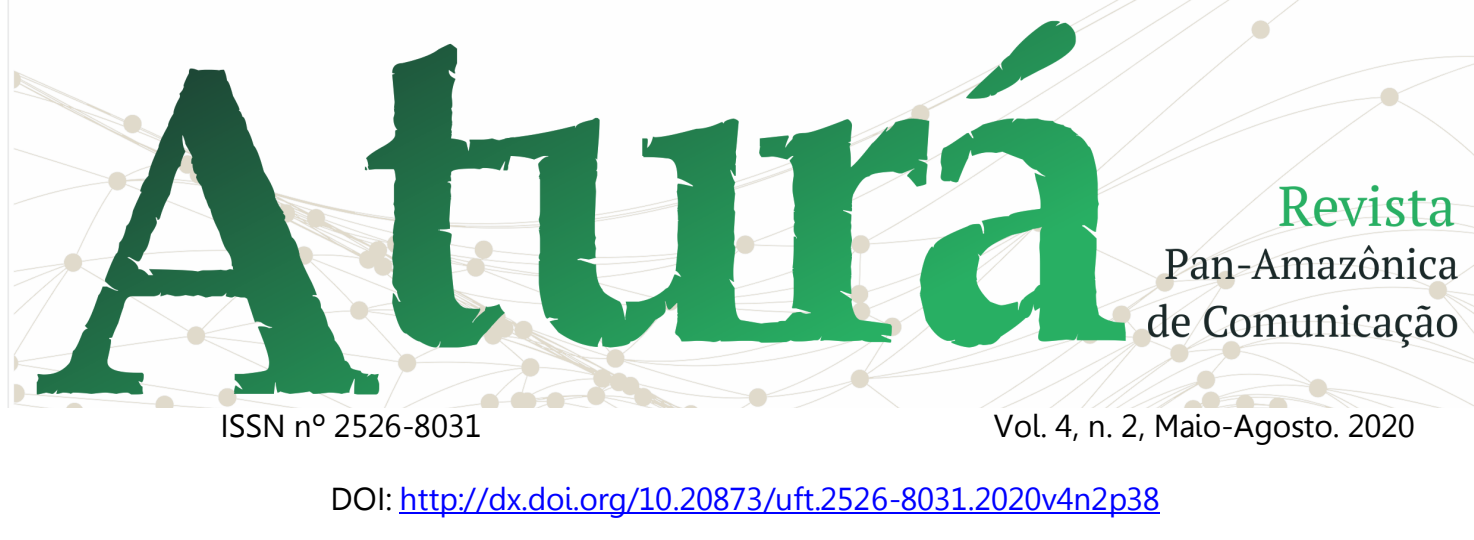

pandemia do Covid-19, conforme é possível observar na tabela a seguir.

\begin{tabular}{|c|c|}
\hline $\begin{array}{l}\text { Manchetes do site do jornal Folha de } \\
\text { São Paulo }\end{array}$ & Data \\
\hline $\begin{array}{l}\text { 1. Argentina suspende participação } \\
\text { em negociações comerciais do } \\
\text { Mercosul }^{16}\end{array}$ & $25 / 04$ \\
\hline $\begin{array}{l}\text { 2. Argentina estende quarentena } \\
\text { em grandes cidades até } 10 \text { de } \\
\text { maio }^{17}\end{array}$ & $25 / 04$ \\
\hline
\end{tabular}

Dados levantados entre 24 e 30 de abril de 2020

18

\section{A Folha de São Paulo apresenta} dois textos diferentes tratando da relação entre governo e Covid-19 na Argentina. O texto número 1 da tabela, escrito por três jornalistas, caracteriza-se como interpretativo e explica que a decisão do governo argentino ocorreu porque a prioridade do país naquele momento era

\footnotetext{
${ }^{16}$ Disponível em:

https://www1.folha.uol.com.br/mercado/2020/04/ argentina-suspende-participacao-nomercosul.shtml?utm source $=$ folha\&utm medium $=$ site\&utm campaign=topicos. Acesso em: 25/04/2020.

17 Disponível em: https://www1.folha.uol.com.br/mundo/2020/04/ar gentina-estende-quarentena-em-grandescidades-ate-10-demaio.shtml?utm source $=$ folha\&utm medium $=$ site \&utm campaign=topicos. Acesso em: 25/04/2020. ${ }_{18}$ Disponível em: https://www.clarin.com/tema/brasil.html. Acesso em: 01/05/2020
}

- combate ao Coronavírus. Após apresentar declarações de fontes oficiais, mais ao final, é apresentada a interpretação dos acontecimentos aos leitores:

\begin{abstract}
A decisão mostra que o distanciamento entre Brasil e Argentina segue ocorrendo. Ambos os países, que têm a seus dois presidentes de costas um para o outro até hoje, Jair Bolsonaro não conversou com seu par argentino, Alberto Fernández - vêm adotando políticas diferentes com relação ao enfrentamento da pandemia e também têm divergências entre si sobre qual deve ser o papel do Mercosul (COLOMBO; COLETTA; CARAM, 2020).
\end{abstract}

Já o texto número 2, escrito pela jornalista Sylvia Colombo, caracteriza-se como informativo, pois apresenta dados, datas e declarações das fontes oficiais sem fazer qualquer interpretação. O lide deixa claro o caráter informativo da matéria: "O presidente da Argentina, Alberto Fernández, anunciou na noite deste sábado (25) que a quarentena obrigatória para conter a disseminação do coronavírus continuará até pelo menos 10 de maio. $\mathrm{O}$ anúncio foi feito a jornalistas na residência presidencial" 


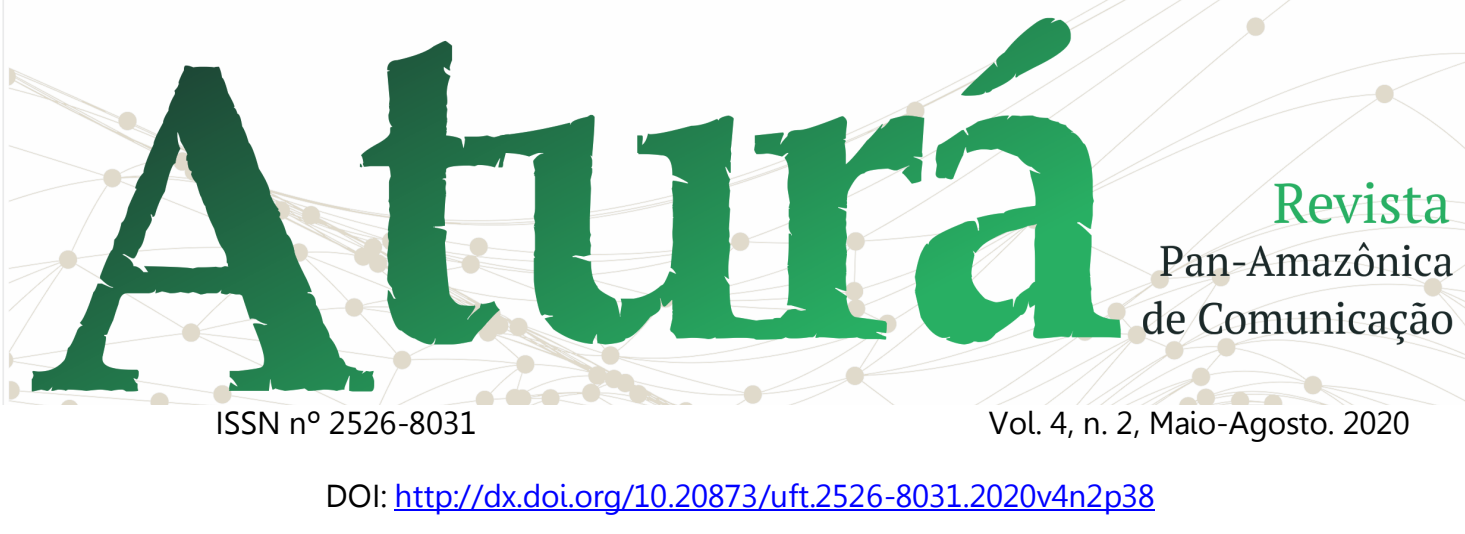

(COLOMBO, 2020). A sequência do texto segue o mesmo caminho de informar 0 leitor o mais objetivamente possível.

\section{Considerações finais}

Aproximamos a atual realidade da ATERR, neste novo contexto (local, mas global), aos pressupostos de Castells (2005, p. 17) o qual afirma que aí:

Após observar o contexto histórico da formação do que hoje chamamos América do Sul, com ênfase nos seus dois maiores países, entende-se que Brasil e Argentina seguem tendo muitas semelhanças históricas. Ambos passaram por processos colonialistas semelhantes, populismos e ditaduras parecidas até se chegar a uma sociedade democrática. No entanto, ficou evidente em meio à pandemia, que as posturas governamentais são diferentes. Isso acabou refletindo no número e nas características das matérias produzidas pelo jornal Clarín sobre a relação do governo brasileiro com a pandemia e nos

textos da Folha de São Paulo sobre as ações do governo argentino.

O grande número de matérias sobre o Brasil no Clarín se justifica, como é possível inferir, devido ao caráter polêmico do presidente brasileiro, que contraria as normas de saúde adotadas pelos demais países da América Latina, que seguem as orientações da OMS. Os números de casos e vítimas do Covid-19 no Brasil e a inação do governo diante disso, também chama a atenção do jornal argentino. Toda essa situação fez com que, nas oito notícias sobre o Brasil no período, o correspondente argentino tivesse que, não só informar e apresentar dados e acontecimentos, mas também interpretá-los para o leitor. São textos que não chegam a se tornar opinativos, mas sim, seguem o padrão interpretativo proposto por Melo (2012). Por outro lado, no Brasil, a Folha de São Paulo, por cobrir o governo argentino, que segue as orientações da OMS e que conta com um presidente discreto, acabou apresentando um texto informativo e outro 


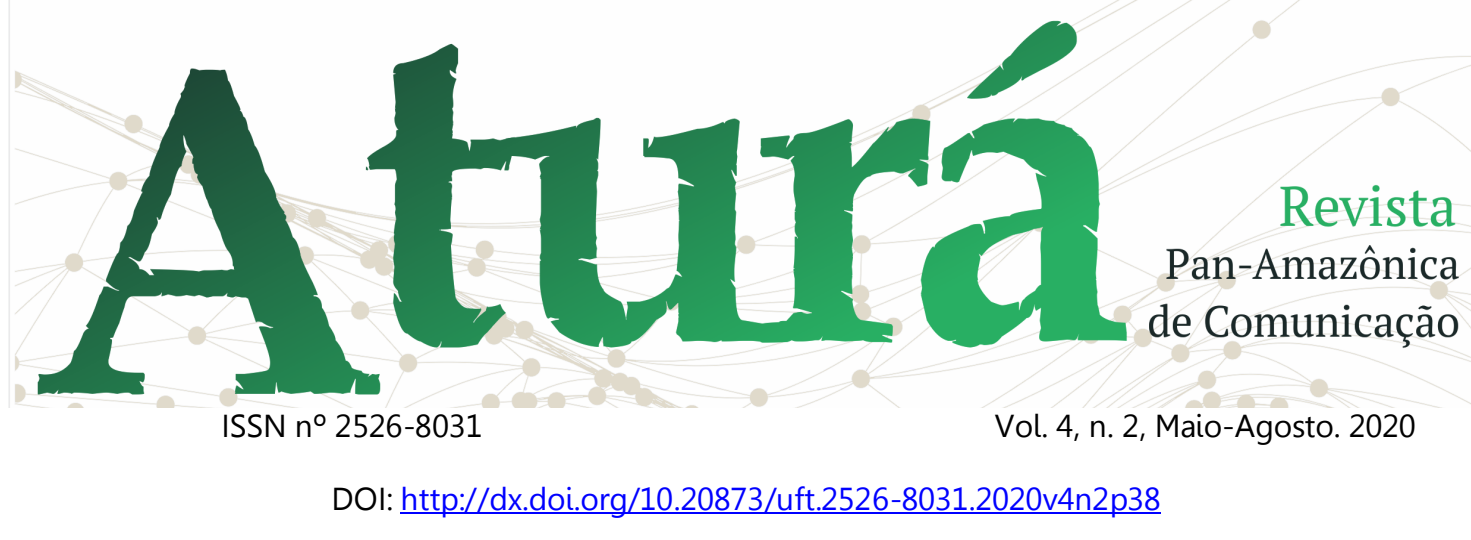

interpretativo. Na segunda categoria, a irresponsáveis pregarem contra a explicação ao leitor foi necessária justamente para demonstrar os diferentes pontos de vista do governo argentino em relação ao brasileiro.

Finaliza-se essa etapa da pesquisa reforçando a importância do jornalismo na América Latina para possibilitar que a informação entre os diferentes países circulem. Acompanhar e pesquisar sobre essa produção é fundamental para que sejam refletidas as práticas jornalísticas nos países e, também, as ações de cada governo. Vale frisar ainda que posturas como as do presidente brasileiro reforçam a necessidade de o jornalista interpretar a realidade, como fez o biógrafo Mário Magalhães ao tentar descrever o que foi o ano de 2018 na história do Brasil. "O Brasil de 2018, por sorte, não é a Alemanha de 1938. Mas herda do passado o ódio e a intolerância extremistas, aqui impregnados nas franjas fanáticas do bolsonarismo. Elas querem mais violência" (MAGALHÃES, 2019, p.246). Enquanto governos autoritários e democracia e colocarem a vida da população em risco fazendo uso e disseminação de notícias falsas no corpo social, caberá aos jornalistas nacionais e estrangeiros apurar, investigar e interpretar suas ações para o mundo. Isso foi possivel de perceber tanto na cobertura do Clarín sobre as declarações e ações polêmicas dos integrantes do governo brasileiro, quanto na cobertura mais informativa sobre os caminhos adotados pelo governo argentino em meio a maior crise desse primeiro quarto de século.

\section{Referências}

ARGENTINA. Folha de S.Paulo. São Paulo: Folha de S.Paulo, 2020. Disponível em: https://m.folha.uol.com.br/folhatopicos/argentina/. Acesso em: $01 / 05 / 2020$

BARBERO, JESUS MARTÍN. Dos meios às mediações. Rio de Janeiro: UFRJ, 2013. BARDIN, Laurence. Análise de conteúdo. São Paulo: Edições 70, 2011. 


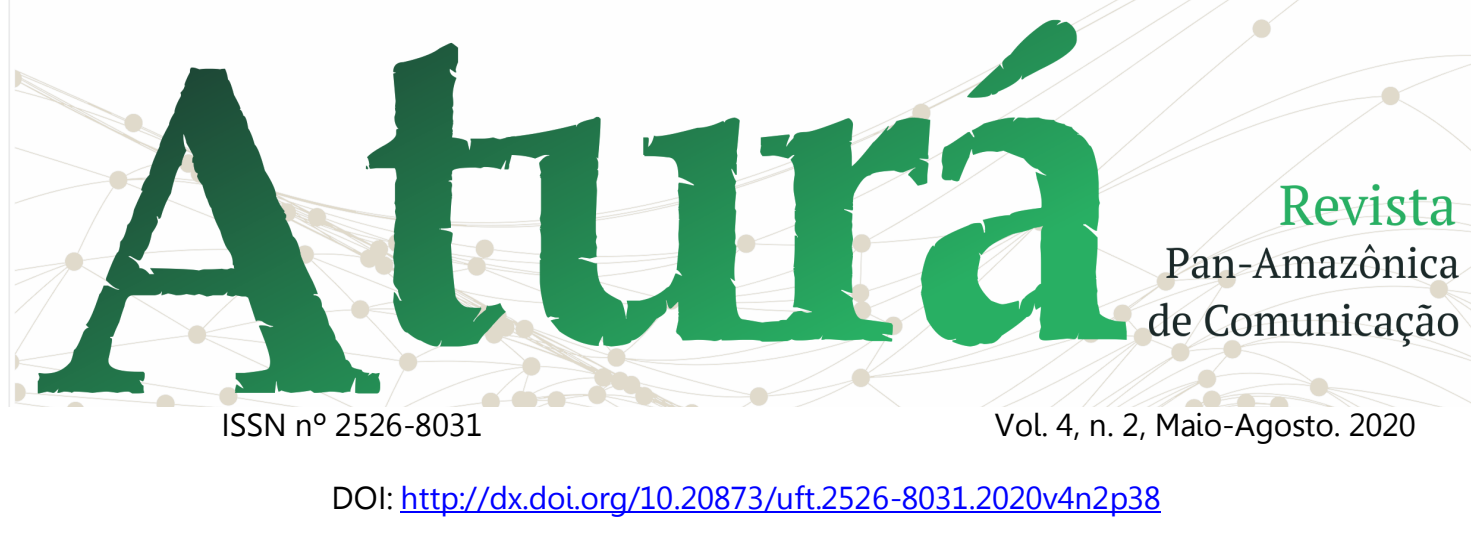

BARRETO, Helton Ricardo. Clarín: de coadjuvante a líder - a trajetória do jornal que se transformou no maior grupo multimídia da Argentina e segundo no mundo hispânico. São Bernardo do Campo: Curso de Pós-Graduação em Comunicação Social da Universidade Metodista de São Paulo, 1999.

BONFIM, Manoel. A América Latina Males de origem. Rio de Janeiro: Topbooks, 1993.

CLARÍN. Brasil. Buenos Aires: Clarín, 2020. Disponível em: https://www.clarin.com/tema/brasil.html. Acesso em: 01/05/2010.

CANCLINI, Néstor García. Culturas híbridas. São Paulo: Edusp, 2013.

COLOMBO, Sylvia. Argentina estende quarentena em grandes cidades até 10 de maio. São Paulo: Folha de S.Paulo, 2020. Disponivel em: https://www1.folha.uol.com.br/mundo/20 20/04/argentina-estende-quarentenaem-grandes-cidades-ate-10-demaio.shtml?utm source $=$ folha\&utm medi um=site\&utm campaign=topicos. Acesso em: 25/04/2020.

COLOMBO, Sylvia; COLETTA, Ricardo Della; CARAM, Bernardo. Argentina suspende participação em negociações comerciais do Mercosul. São Paulo: Folha de S.Paulo, 2020. Disponível em: https://www1.folha.uol.com.br/mercado/2 020/04/argentina-suspende-participacaono-

mercosul.shtml?utm source $=$ folha\&utm medium =site\&utm campaign=topicos.

Acesso em: 25/04/2020.

CUNHA, Luiz Cláudio. O sequestro dos uruguaios. Porto Alegre: L\&PM, 2008.

FOLHA DE S.PAULO. Folha cresce e lidera circulação entre jornais do país em 2019. São Paulo, Folha de S.Paulo, 2020. Disponível em: https://www1.folha.uol.com.br/poder/202 0/01/folha-cresce-e-lidera-circulacaoentre-jornais-do-pais-em-2019.shtml. Acesso em: 30 de abril de 2020.

GALEANO, Eduardo. As veias abertas da América Latina. São Paulo: Paz e Terra, 1989.

HERSCOVITZ, Heloiza Golbspan. Análise de conteúdo em jornalismo. In: LAGO, Cláudia.; BENETTI, Márcia. (Orgs.). Metodologia de pesquisa em jornalismo. Petrópolis: Vozes, 2008. p.123-142.

MAGALHÃES, Mário. Sobre lutas e lágrimas - uma biografai de 2018. Rio de Janeiro: Record, 2019.

MARTINO, Luis Mauro Sá. Métodos de pesquisa em comunicação - projetos, ideias, práticas. Petrópolis: Vozes, 2018.

MARTINS, Franklin. Jornalismo político. São Paulo: Contexto, 2011. 


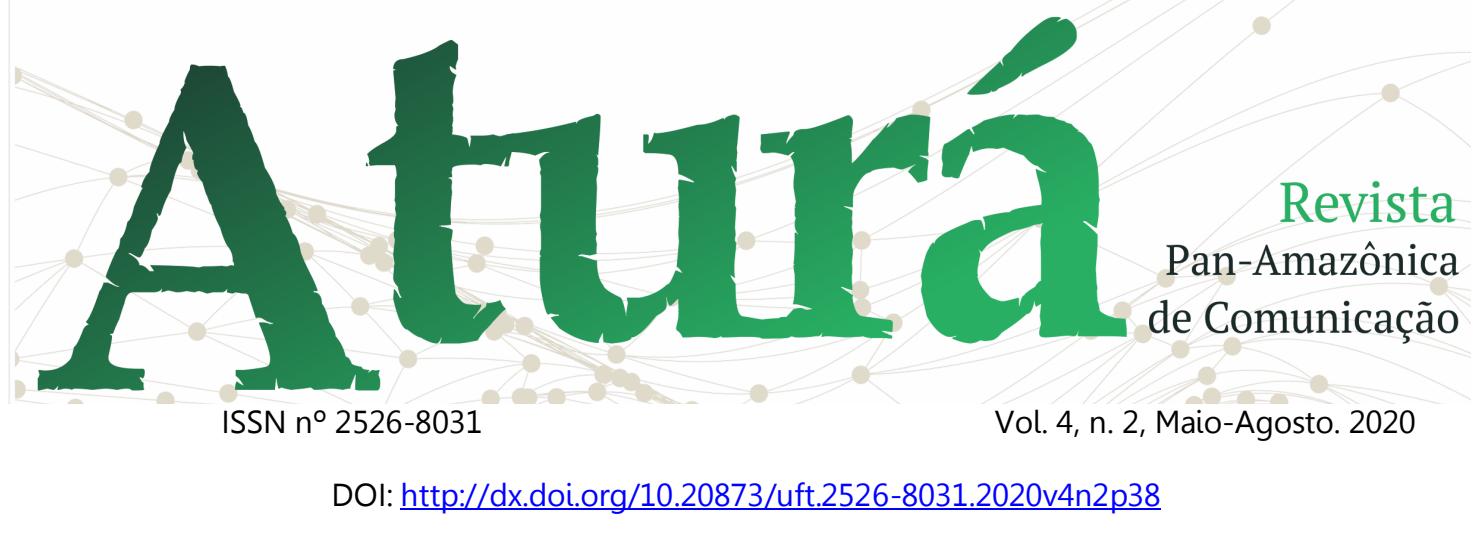

MELO, José Marques de. Gêneros jornalísticos - teoria e práxis. Blumenau: EdiFurb, 2012.

NEJAMKIS, Guido. Coronvirus en Brasil: Golpeado tras las acusaciones de Sergio Moro, Jair Bolsonaro busca contener la crisis. Buenos Aires: Clarín, 2020. Disponível em: https://www.clarin.com/mundo/golpeado -acusaciones-sergio-moro-jair-bolsonarobusca-contener-crisis 0 o56pEdztc.html. Acesso em: 25/04/2020.

NEJAMKIS, Guido. En medio de una crisis política: Coronavirus en Brasil: llega a 4.205 muertes, con más de 61.888 casos de Covid-19. Buenos Aires: Clarín, 2020. Disponível em: https://www.clarin.com/mundo/coronavir us-brasil-llega-4-205-muertes-61-888casos-covid-19 0 0FaNUX6dz.html. Acesso em: 26/04/2020.

NEJAMKIS, Guido. Coronavirus en Brasil: "No queremos convertirnos en una Argentina", dijo el ministro de Economía de Bolsonaro. Buenos Aires: Clarín, 2020. Disponivel em: https://www.clarin.com/mundo/coronavir us-brasil-queremos-convertirnosargentina-dijo-ministro-economiabolsonaro 0 dMrpYKWpx.html. Acesso em: 27/04/2020.

NEJAMKIS, Guido. Jair Bolsonaro, luego de que Brasil superó a China en cantidad de muertos por el coronavirus: "Lo lamento, ¿qué quiere que haga?". Buenos Aires: Clarín, 2020. Disponível em:

https://www.clarin.com/mundo/jairbolsonaro-luego-brasil-supero-chinacantidad-muertos-coronavirus-lamentoquiere-haga- $0 \mathrm{~d}$ HTu-d7s.html. Acesso em: 28/04/2020.

NEJAMKIS, Guido. Coronavirus em Brasil: Jair Bolsonaro se niega a mostrar los tests de Covid-19. Buenos Aires: Clarín, 2020. Disponível

em: https://www.clarin.com/mundo/coronavir us-brasil-jair-bolsonaro-niega-mostrartests-covid-19 0 9V098P58-.html. Acesso em: 29/04/2010.

NEJAMKIS, Guido. Ya hay 5017 fallecidos Jair Bolsonaro, luego de que Brasil superó a China en cantidad de muertos por el coronavirus: "Lo lamento, ¿qué quiere que haga?". Buenos Aires: Clarín, 2020. Disponível em: https://www.clarin.com/mundo/coronavir us-brasil-lamento-quieren-haga-mesiashago-milagros-defiende-jairbolsonaro 0 0OfqkG87m.html. Acesso em: 29/04/2020.

NEJAMKIS, Guido. Coronavirus en Brasil: Jair Bolsonaro dijo que la Organización Mundial de la Salud incentiva la masturbación de niños. Buenos Aires: Clarín, 2020. Disponível em: https://www.clarin.com/mundo/coronavir us-brasil-jair-bolsonaro-dijoorganizacion-mundial-salud-incentivamasturbacion-ninos 0 S7kG9U6XD.html. Acesso em: 30/04/2020. 


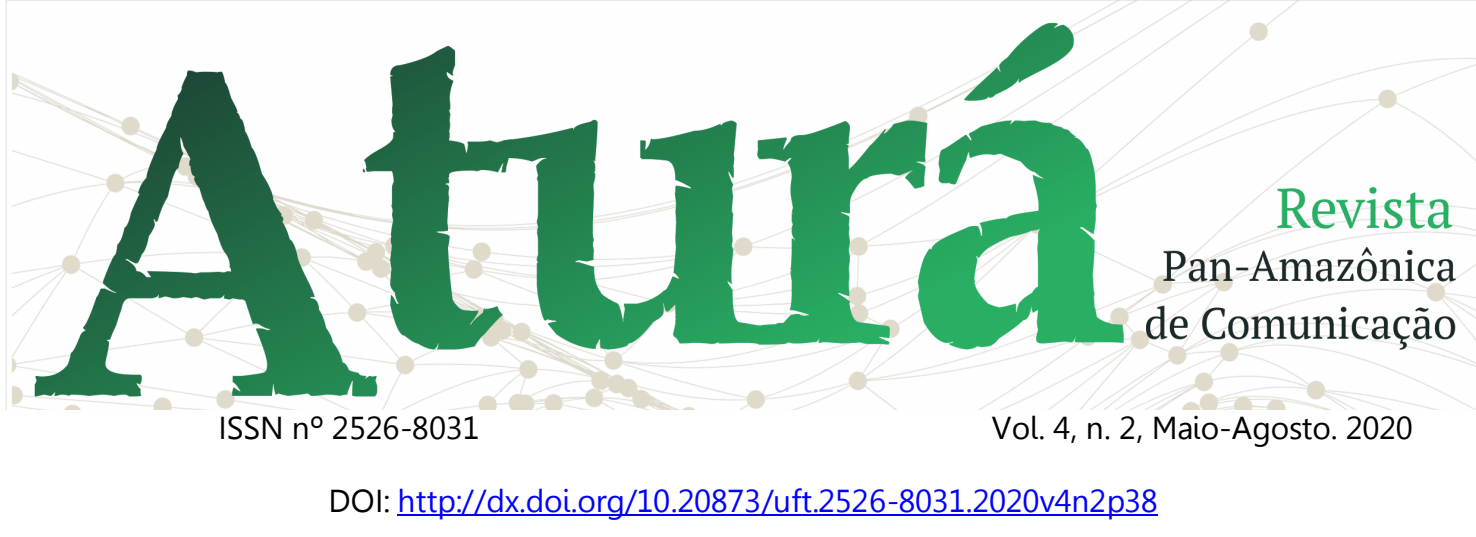

NEJAMKIS, Guido. Coronavirus en Brasil: más 7.218 nuevos casos y 435 muertes en 24 horas. Buenos Aires: Clarín, 2020. Disponível em: https://www.clarin.com/mundo/coronavir us-brasil-7-218-nuevos-casos-435-

muertes-24-horas 0 dq3VHGroa.html. Acesso em: 30 de abril de 2020.

RIBEIRO, Darcy. América Latina: a pátria grande. Rio de Janeiro: Fundação Darcy Ribeiro, 2012.

RIBEIRO, Darcy. As Américas e a civilização. Petrópolis: Vozes, 1977.

TRAQUINA, Nelson. Teorias do jornalismo - A tribo jornalística - uma comunidade transnacional. Florianópolis: Insular, 2005.

WEBER, Andréa; STURZA, Eliana. Línguas e imaginário na fronteira platina. In: Raddatz, Vera Lucia Spacil; MÜLLER, Karla Maria. Comunicação, cultura e fronteiras. ljuí: Unijuí, 2015. 